\title{
Laboreal
}

Volume $12 \mathrm{~N}^{\circ} 1$ | 2016

Os Equipamentos de Proteção Individual (EPI):

protetores, mas nem sempre

\section{Ensaio de análise da distinção «psicologia em laboratório», «psicologia no terreno»}

Tentativa de análisis de la distinción entre la «Psicología en el laboratorio» «Psicología en el campo»

Un essai d'analyse de la distinction " psychologie en laboratoire " «psychologie sur le terrain»

An essay on the analysis to differentiate "psychology in the lab», "psychology in the field»

\section{Maurice Reuchlin}

Tradutor. João Viana Jorge

\section{(2) OpenEdition}

\section{Journals}

\section{Edição electrónica}

URL: http://journals.openedition.org/laboreal/3378

DOI: $10.4000 /$ laboreal.3378

ISSN: 1646-5237

Editora

Universidade do Porto

Refêrencia eletrónica

Maurice Reuchlin, «Ensaio de análise da distinção «psicologia em laboratório», «psicologia no terreno» », Laboreal [Online], Volume $12 N^{0} 1$ | 2016, posto online no dia 01 julho 2016, consultado o 24 setembro 2020. URL : http://journals.openedition.org/laboreal/3378 ; DOI : https://doi.org/10.4000/ laboreal.3378

Este documento foi criado de forma automática no dia 24 setembro 2020.

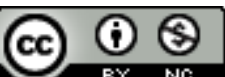

Laboreal está licenciado com uma Licença Creative Commons - Atribuição-NãoComercial 4.0 Internacional. 


\section{Ensaio de análise da distinção «psicologia em laboratório», «psicologia no terreno»}

Tentativa de análisis de la distinción entre la «Psicología en el laboratorio» «Psicología en el campo»

Un essai d'analyse de la distinction " psychologie en laboratoire» " psychologie sur le terrain"

An essay on the analysis to differentiate "psychology in the lab», "psychology in the field»

\section{Maurice Reuchlin}

Tradução : João Viana Jorge

\section{REFERÊNCIA}

Texto original [1]: Reuchlin, M. (1978). Un essai d'analyse de la distinction " psychologie en laboratoire » «psychologie sur le terrain». Le Travail Humain, 45, 2, 307-324.

\section{NOTA DO AUTOR}

Os nossos trabalhos também utilizam os meios que devemos à EPHE (3a secção), ao CNRS (ERA 79), ao INOP (CNAM). Este texto é um resumo da apresentação oral. Teve em conta certas críticas e sugestões que a apresentação suscitou. Agradeço aos colegas que participaram nessa discussão.

1 I. Pode-se tentar resumir, no fim deste ciclo de estudos, as principais características a partir das quais diversos contribuintes propuseram, implícita ou explicitamente, 
distinguir uma psicologia em laboratório de uma psicologia no terreno (mesmo quando esta distinção foi apresentada com críticas e reservas, o que foi frequentemente o caso).

Poder-se-á a seguir questionar se as características distintivas são compatíveis com uma diferenciação numa só dimensão definida pelos polos «laboratório» - «terreno». Sugerir-se-á que diversas dimensões parecem necessárias, das quais algumas podem distinguir trabalhos listados, em primeira, aproximação, numa ou noutra das duas categorias iniciais.

1. A frequência com a qual o sujeito se encontrou colocado anteriormente na situação em que está quando o psicólogo o observa constitui uma primeira característica distintiva. Em geral esta frequência parece elevada nos trabalhos no terreno, enquanto que parece ser nula nos trabalhos em laboratório. Note-se todavia que o ter em conta, no laboratório, a frequência de utilização na linguagem das palavras empregadas como material experimental constitui um exemplo que introduz uma nuance nesta primeira distinção.

2. Uma outra característica distintiva reside em que, no terreno, o sujeito observado pelo psicólogo executa em geral atos que têm para ele consequências que vão para além do período de observação. Pelo contrário, a deontologia do experimentador de laboratório impõe-lhe a obrigação de evitar que a atividade do sujeito quando da experiência tenha qualquer efeito posteriormente.

3. Poderiam descrever-se situações, no terreno, pelo facto de tornarem possíveis as transferências. É duvidoso que esta característica distinga estas duas categorias de situação: em laboratório o sujeito não pode reagir de outro modo que não seja o uso de esquemas de resposta que tenham sido construídos no decurso de situações anteriores. Mas pode dizer-se que as pesquisas em laboratório tendem pelo menos a minimizar esses efeitos de transferência (utilização de sílabas desprovidas de sentido, perceção de estímulos não significativos, etc.) enquanto que o psicólogo no terreno, mesmo quando imigra provisoriamente para o laboratório tenta nele montar situações que conservam as características da situação no terreno, julgadas essenciais.

4. As situações de terreno parecem pôr em jogo um campo de constrangimentos muito mais amplo e complexo que as situações de laboratório. O sujeito submetido a uma experiência de tempos de reação e o automobilista que tem de travar perante um sinal vermelho não estão, desse ponto de vista, na mesma situação. No segundo incidem com efeito, implicitamente constrangimentos muito mais numerosos que no primeiro.

5. Este último exemplo introduz, por outro lado, uma característica diferenciadora muito importante: a intervenção de valores, de estereótipos sociais nas condutas observadas no terreno. Esta intervenção pode ser suscitada em laboratório (perceção e memorização de textos que estejam de acordo ou em desacordo, por exemplo com as escolhas políticas do sujeito. Mas a intervenção destes fatores é com toda a evidência muito mais geral e muito mais determinante no terreno.

6. Um aspeto particular da intervenção destes fatores sociais merece ser tratado à parte: a importância das informações implícitas. Desempenham um papel essencial nas situações de terreno. Permitem nomeadamente abreviar consideravelmente as mensagens trocadas entre sujeitos pertencentes a um mesmo meio, tornar perfeitamente claras situações que seriam equívocas se nos limitarmos a utilizar as informações explícitas, etc. Em laboratório, pelo contrário, elas são em princípio excluídas: a situação tem em vista ser inteiramente definida por condições explícitas a fim de que se possam explicar sem ambiguidade, por essas condições, as condutas observadas.

3 Enfim, evoca-se frequentemente, quando se procura distinguir entre terreno e laboratório, uma característica respeitante ao «tamanho» das variáveis utilizadas, ou, o que vem a dar no mesmo, o «nível» da análise. Uma hierarquia de variáveis de tamanho 
crescente (ou de níveis de análise cada vez mais "molar") é constituída por exemplo assim: fenómenos bioquímicos no seio do neurónio, sinais bioelétricos circulantes nas vias nervosas, capacidades funcionais elementares (perceção do semelhante e do diferente, memória do trabalho), aprendizagem da leitura, sucesso escolar. Admite-se em geral que os primeiros destes temas são estudados em laboratório, os últimos no terreno. De facto é muito difícil dar uma definição geral satisfatória do que é uma microvariável, uma análise molecular sem fazer intervir as características antes enumeradas. Poderia convir dizer que um fenómeno A se manifesta por variáveis de tamanho mais elevado que um fenómeno B (ou corresponde a um nível de análise mais elevado) se se pode estabelecer que B faz parte de um conjunto de condições das quais, pelo menos algumas devem necessariamente ser cumpridas para que se produza A. As condições de nível B são necessárias mas não suficientes para a aparição de A. Além disso, diferentes combinações de nível B podem permitir a aparição de A (função vicariante).

Esta característica incide antes de tudo numa diferença de orientação na démarche do investigador. Uns escolhem partir do «simples», do «elementar» deixando à psicologia a reconstituição do "complexo» como objetivo longínquo de acordo com uma démarche cartesiana; outros escolhem tentar ler o «simples» construído a partir de um "complexo" primitivo e dado, de acordo com uma démarche "bachelardiana".

II. Uma só dimensão como a de «psicologia em laboratório» - «psicologia no terreno» será suficiente para resumir as diferentes características que acabam de ser enumeradas para de certo modo as «explicar» tentando pôr em evidência o que têm de comum? Se bem que essas diferentes características apresentem provavelmente correlações entre elas fazê-las retornar a uma dimensão única constitui uma aproximação demasiado grosseira. Além disso a distinção «laboratório-terreno» não é forçosamente a mais bem escolhida para descrever esses factos. Esta simples contraposição de lugares mascara as diferenciações mais fundamentais que estabelecem aliás distinções tanto no seio dos trabalhos «de laboratório» como no seio dos trabalhos «de terreno». Propõem-se para discussão três desses fatores de diferenciação.

1. Em primeiro lugar pode dizer-se que os investigadores parecem adotar atitudes diferentes face à ideia segundo a qual as condutas que a psicologia estuda são sistemas (Von Bertallanffy) ou estruturas (Piaget). São favoráveis a esta ideia os que se esforçam por isolar os factos estudados do seu contexto, por observar as leis que se espera que se verifiquem em contextos muito diferentes («funções»), por tenderem para experiências «bernardianas» (uma só variável independente, uma só variável dependente, mantendo as restantes variáveis constantes), por negligenciar ou evitar as interações (os planos fisherianos foram, nesta perspetiva, um método que permitiu realizar diversas experiências bernardianas simultânea e, economicamente, mais do que um meio de pôr em evidência interações suscetíveis de voltar a pôr em causa o próprio princípio das experiências bernardianas).

2. Uma estrutura define-se, para os estruturalistas, pelas leis que caracterizam o sistema de transformação que ela constitui, independentemente das propriedades dos elementos que «realizam» esse sistema (ver nomeadamente Piaget, O estruturalismo, 1968, p.6). Podem adotar-se atitudes diferentes face a essa independência e esse é um segundo fator de diferenciação dos trabalhos de que falámos. É bem sabido que Piaget postula essa independência: ele reencontra as mesmas leis (agrupamentos ou grupos) em níveis diferentes do desenvolvimento; reencontra em cada um desses níveis estruturas que se realizam sobre materiais muito diferentes (INRC, etc.); utiliza certos isomorfismos de que se apercebe entre a filogénese, a história das ciências e a ontogénese. Mas esta aceitação da 
ideia segundo a qual as leis são independentes dos materiais aos quais se aplicam e que assim as realizam (, observa-se em correntes de trabalhos muito diferentes. O «teorema da indiferença do indicador» de C. Spearman é disso um exemplo (As aptidões do homem, trad. Franc., p.153). Ilustra-se igualmente no emprego do singular para definir as funções da psicologia experimental clássica, que fala da perceção, da aprendizagem, da motivação, etc. Este modo de colocar os problemas suscitou algumas dificuldades e podemos compreender certos aspetos dos trabalhos ditos «de terreno» como as manifestações de uma tendência a tomar por objeto, estruturas realizadas. Designaremos por essa expressão que, para um estruturalista evidenciaria uma contradição interna, as estruturas cujas leis de funcionamento podem variar com as propriedades dos conteúdos aos quais se aplicam e que por aí mesmo se realizam. Sabe-se por exemplo que J.-B. Grize e B. Matalon, tentando estudar o «pensamento natural» e experimentando com a implicação chegam à ideia de que «para o pensamento corrente, a admissibilidade de uma implicação p J q é entre outras, função da pertença dos conteúdos do implicante $p$ e do implicado $q$ a um domínio comum» (volume XVI de Etudes d'épistémologie génétique). Mas não parece que se tenha conseguido, no quadro do estruturalismo, definir o que podia ser um conteúdo e um domínio, apesar das propostas de Piaget respeitantes aos sucessivos níveis de abstração reflexiva. A solução passa talvez pelo reconhecimento de uma importação empírica no funcionamento das estruturas mesmo que isso constitua uma rotura com os postulados fundamentais do estruturalismo. É em todo o caso o que propusemos noutros lados a respeito deste problema do «pensamento natural» (Journal de Psychologie, 1973, 389-408). Todavia esta evolução não se observa ainda aí somente quando se aproxima de uma psicologia «de terreno». Observa-se também «em laboratório». Poder-se-ia evocar, de um modo geral, uma tendência das grandes funções clássicas a se diversificarem quando se estuda o seu funcionamento em condições diferentes. Uma representação mais precisa é fornecida pela postura em evidência da intervenção das informações semânticas. Esta intervenção foi estabelecida no funcionamento da memória por trabalhos cuja orientação é o oposto de antigos trabalhos tomando como regra não utilizar senão um material não significativo. A mesma intervenção foi igualmente estabelecida no decurso da descodificação sintática: se é verdade que uma sequência Substantivo-Verbo-Substantivo tende a ser descodificada sobre o modelo sintático SujeitoVerbo-Objeto, essa descodificação tem todavia em conta o sentido das palavras utilizadas (Viatura-Lavar-Rapaz) não é descodificada sintaticamente como (Menina-Arrastar-Rapaz). Uma negação lexical (codificada por palavras como perder, levantar, etc.) funciona ao mesmo tempo que uma negação sintática.

3. Uma terceira distinção sugerida em primeira aproximação pelo conjunto dos caracteres distinguindo uma psicologia «em laboratório» de uma psicologia «de terreno» atenua essa distinção e intervém no seio desses dois grupos. Trata-se da atitude adotada face à ideia segundo a qual o psicólogo tem por objeto estruturas reais, quer dizer que se lhe impõem como objetos dotados de um certo grau de autonomia, estruturas das quais se trata primeiro de as «descobrir» e cuja montagem se operou no decurso da filogénese e da ontogénese. Esta atitude, consistindo em ver nos objetos do psicólogo factos próprios ao momento da observação e explicáveis (em princípio) pelas evoluções da espécie e do indivíduo, tende a opor-se a uma atitude inspirando-se mais numa epistemologia físico-química baseada nas propriedades intrínsecas e permanentes dos objetos estudados. Poder-se-ia perguntar se a psicologia «de laboratório» clássica não se constituiu mais sobre este segundo modelo em conformidade com uma fisiologia tendo acedido no séc. XIX ao estatuto de ciência tomando por modelo a física do seu tempo. Um modelo diferente era o oferecido por Darwin. A distinção aqui proposta situa-se no prolongamento das diferenciações, ou mesmo oposições que marcaram uma psicologia que definiu as suas regras experimentais sobre o modelo das regras da experimentação físico-química (do séc. XIX) e uma psicologia que se inspirou no evolucionismo darwiniano situando-se assim na vizinhança das ciências «naturais» (controvérsia Titchner-Baldwin entre outros). 
6 As estruturas cuja realidade pode ser assim reconhecida ou negada situam-se, em primeiro lugar, nas situações utilizadas pelos psicólogos.

7 O reconhecimento da realidade dessas estruturas da situação pode tomar formas muito diferentes. Pode conduzir certos psicólogos a recomendar um apanhado global, tão completo quanto possível, de tudo o que constitui as condições de vida dos sujeitos estudados tais como se apresentam na altura e com o sentido que lhes confere a sua história e as suas perspetivas de evolução. Numa outra perspetiva um determinado emprego dos métodos de inquérito pode inspirar-se na mesma atitude. Consistirá em comparar grupos definidos simultaneamente sob o ângulo de diversas características (rendimento, nível cultural, qualificação profissional, por exemplo), justificando-se pelo facto de que se trata de uma «realidade» pelo menos à escala estatística e no momento do inquérito. As análises de regressão, possíveis neste caso, não negam nunca a existência desta «estruturação real». Fornecem unicamente descrições diferentes, eventualmente parcelares como «cortes» planos em diferentes direções podem facilitar a descrição de um objeto sólido.

8 A realidade das estruturas da situação pode ser negada e essa negação pode, também ela, tomar formas diferentes. Um primeiro exemplo pode encontrar-se na liberdade que toma o experimentador de fazer variar com independência os diferentes valores suscetíveis de serem atribuídos às suas variáveis independentes. Esta regra experimental não encara a possibilidade de que certas combinações somente das variáveis independentes possuam uma realidade «na natureza». O aparecimento ulterior de interações poderia ser compreendido como a colocação em evidência do carácter naturalmente privilegiado de certas combinações dos valores das variáveis independentes. Nunca ela é assim interpretada. Um segundo exemplo remeter-nos-á para os métodos de inquérito, utilizados num outro espírito. As ligações entre rendimento, nível cultural e qualificação profissional foram acima tomados como exemplo de uma estruturação «real». Estas ligações não sendo senão estatísticas, pode tentar-se constituir amostras de sujeitos para os quais estas três variáveis (por exemplo) serão ortogonalizadas. Isso nem sempre é possível. Mesmo quando isso se consegue, a generabilidade dos resultados observados utilizando sistematicamente sujeitos atípicos é sempre muito incerta.

9 Mas a existência de estruturas «reais» pode também ser invocada ou rejeitada no que ao sujeito concerne.

É assim que Piaget «descobre» as estruturas das quais descreve o funcionamento. Sabese que, para Piaget, a inteligência se situa no prolongamento dos mecanismos biológicos de adaptação e não admirará vê-lo adotar esta posição «naturalista». Tal posição é igualmente coerente com a sua atitude muito crítica face à imagem que produz da análise estatística (Prefácio, com Inhelder de L'image mentale chez l'enfant) e mesmo da experiência organizada $\left.{ }^{2}{ }^{2}\right]$. A «liberdade» do experimentador pode encontrar limites na existência de estruturas reais do sujeito. A ideia é muito bem ilustrada por $\mathrm{M}$. Blancheteau num artigo intitulado: «Les limites éthologiques de la possibilite de liaison conditionnelle» (Année psychologique, 1975,75, 493-512). Sabe-se que a teoria clássica do condicionamento admite uma lei dita da «equipotencialidade dos estímulos» segundo a qual não importa qual estímulo percetível pode substituir-se ao estímulo absoluto para produzir a mesma resposta. Vê-se que esta lei é uma negação da ideia segundo a qual estruturas determinadas (pelas filogénese e ontogénese) existiriam no indivíduo entre determinados estímulos e entre certos estímulos e certas respostas. Ora Blancheteau 
mostra que não se pode condicionar seja o que for ao que quer que seja, o que volta a estabelecer a realidade de tais estruturas. Para melhor definir os mecanismos do condicionamento, conclui Blancheteau, é preciso saber qual é o modo de vida dos animais.

III. Se o psicólogo se propõe como objetivo, longínquo que seja, explicar as condutas «habituais» ou «naturais» dos organismos que estuda, não escapará à necessidade de tomar em consideração estruturas ao mesmo tempo concretizadas e reais. A démarche que permite aceder ao conhecimento dessas estruturas pode muito bem comportar ciclos de aproximações sucessivas que foram por vezes evocadas sob a forma de uma alternância entre estudos «de laboratório» e estudos «de terreno».

Uma psicologia científica não pode apreender direta e globalmente uma estrutura. As relações, correlações, interações entre um pequeno número de variáveis (duas no limite) podem ser vias de acesso a estruturas mais extensas e complexas se para que as aproximações sucessivas e o postulado da existência de tais estruturas guia as hipóteses que suscitam estas observações ou experiências parciais e a interpretação dos seus resultados. O estudo das interações entre as leis formais das estruturas e as propriedades dos elementos que elas realizam pode utilizar etapas nas quais uma estrutura de dada forma é estudada sob realizações diferentes, um conteúdo de uma dada natureza é utilizado para realizar estruturas diversas, esta démarche não sendo útil a menos que seja uma via de acesso ao estudo da interação e não, em sentido inverso, a primeira etapa de uma análise reducionista. Identicamente, a descoberta de estruturas reais poderá fazer-se por constatação do inadequado de estruturas hipotéticas construídas «livremente». Mas far-se-á sem qualquer dúvida mais depressa se as hipóteses inicialmente «livres» se inspirarem menos numa problemática de tipo físicoquímico e mais numa problemática naturalista.

Aproximações sucessivas não têm interesse senão se convergirem. Para que as aproximações sucessivas dos psicólogos «de laboratório» e «de terreno» tenham uma possibilidade de convergir, é sem dúvida necessário que uns e outros se ponham de acordo sobre o tipo de objetos que visam: estruturas de condutas (e portanto de situações) tendo propriedades funcionais dependentes ao mesmo tempo das leis formais que as definem enquanto estruturas e propriedades dos elementos que as realizam, resultando essas estruturas realizadas observáveis de montagens e de seleções operadas no decurso da história da espécie e na do indivíduo.

\section{NOTAS}

1. No texto original, Maurice Reuchlin refere obras de autores sem ter apresentado uma lista de referências no final do texto. Assim esta tradução respeita a sua forma original. o leitor poderá encontrar facilmente referências desses autores na internet.

2. «Se arrancais com um plano experimental falseareis tudo, necessariamente. Tudo o que é realmente interessante para vós deve necessariamente cair fora de não importa que plano tereis estabelecido previamente. A razão pela qual não tenho planos experimentais é a de que estou a 
pesquisar coisas novas. Para mim uma experiência é bem sucedida quando encontro qualquer coisa de inesperado, totalmente imprevista. É então que as coisas se tornam interessantes» (R. I. Evans, Jean Piaget, The man and his ideas, New York, Dutton, 1973, p. 36, tradução livre).

\section{AUTORES}

\section{MAURICE REUCHLIN}

Universidade René-Descartes 